The effects of interprofessional education - Self-reported professional competence among prehospital emergency care nursing students on the point of graduation - A cross-sectional study

Castren, $\mathrm{M}$.

2017-05

Castren , M , Mäkinen , M T , Nilsson , J \& Lindstrom , V 2017 , ' The effects of interprofessional education - Self-reported professional competence among prehospital emergency care nursing students on the point of graduation - A cross-sectional study ' , International Emergency Nursing , vol. 32 , pp. 50-55 . https://doi.org/10.1016/j.ienj.2017.02.004

http://hdl.handle.net/10138/237091

https://doi.org/10.1016/j.ienj.2017.02.004

publishedVersion

Downloaded from Helda, University of Helsinki institutional repository.

This is an electronic reprint of the original article.

This reprint may differ from the original in pagination and typographic detail.

Please cite the original version. 


\title{
The effects of interprofessional education - Self-reported professional competence among prehospital emergency care nursing students on the point of graduation - A cross-sectional study
}

\author{
M. Castrèn ${ }^{\mathrm{a}, \mathrm{b}}$, M. Mäkinen ${ }^{\mathrm{a}}$, J. Nilsson ${ }^{\mathrm{c}}$, V. Lindström ${ }^{\mathrm{d}, *}$ \\ ${ }^{a}$ Department of Emergency Medicine and Services, Helsinki University Hospital and Helsinki University, Helsinki, Finland \\ ${ }^{\mathrm{b}}$ Karolinska Institutet, Department of Clinical Science and Education, Södersjukhuset, Stockholm, Sweden \\ 'Sophiahemmet University, Stockholm, Sweden \& The Department of Health Sciences, Faculty of Health, Science and Technology, Karlstad University, Karlstad, Sweden \\ ${ }^{\mathrm{d}}$ Karolinska Institutet, Department of Neurobiology, Care Sciences and Society, Section of Care Science E Academic EMS Stockholm, Sweden
}

\section{A R T I C L E I N F O}

\section{Article history:}

Received 18 September 2016

Received in revised form 16 February 2017

Accepted 20 February 2017

\section{Keywords:}

NPC Scale, Nurse Professional Competence

Scale

Nurse education

Self-assessment

Prehospital

Emergency medical services

Prehospital emergency care nurse

\begin{abstract}
A B S T R A C T
The aim of the study was to investigate whether interprofessional education (IPE) and interprofessional collaboration (IPC) during the educational program had an impact on prehospital emergency care nurses' (PECN) self-reported competence towards the end of the study program. A cross-sectional study using the Nurse Professional Competence (NPC) Scale was conducted. A comparison was made between PECN students from Finland who experienced IPE and IPC in the clinical setting, and PECN students from Sweden with no IPE and a low level of IPC. Forty-one students participated (Finnish $n=19$, Swedish $n=22$ ). The self-reported competence was higher among the Swedish students. A statistically significant difference was found in one competence area; legislation in nursing and safety planning $(p<0.01)$. The Finnish students scored significantly higher on items related to interprofessional teamwork. Both the Swedish and Finnish students' self-reported professional competence was relatively low according to the NPC Scale. Increasing IPC and IPE in combination with offering a higher academic degree may be an option when developing the ambulance service and the study program for PECNs.
\end{abstract}

(c) 2017 Elsevier Ltd. All rights reserved.

\section{Introduction}

In the 1980s, the World Health Organisation raised the issue of interprofessional education (IPE) and said that it would be an advantage for undergraduate students to train together since they would work together in their professional lives [1]. Students who participate in IPE strengthen their professional identity, gain a deeper understanding of the importance of teamwork, and acquire increased capability in interdisciplinary communication [2-4]. IPE may also have a positive effect on patient experience of care and reduction of clinical errors. Nevertheless, there is little evi-

Abbreviations: CA, Competence area; EMT, Emergency medical technicians; IPE, Interprofessional education; IPC, Interprofessional collaboration; NPC Scale, Nurse Professional Competence Scale; PECN, Prehospital emergency care nurse; RN, Registered nurse.

* Corresponding author at: Karolinska Institutet, Department of Neurobiology, Care Sciences and Society, Section of Care science, Alfred Nobels allé 23, SE-141 83 Huddinge, Sweden.

E-mail address: veronica.lindstrom@ki.se (V. Lindström). dence to draw any generalizable conclusions about IPE effectiveness on patient outcome $[3,5]$.

While IPE has been identified as an important approach for training in collaboration among students, interprofessional collaboration (IPC) among professional health care providers has been identified as an important policy approach for addressing patient safety issues [1]. It is known that IPC is more likely to occur if the working environment features knowledge about IPC, a positive nurse-physician relationship, and shared responsibility for the patient care [6-8]. Structural empowerment, authentic leadership and a professional nursing practice environment may also enhance IPC in the clinical setting [9]. How the IPE is affected by the level of IPC in the clinical setting has not been the subject of much research, and there is a need to explore if and how IPE in the curriculum and the level of IPC in the clinical setting affect students' professional competence. Therefore, the aim of the study was to investigate whether IPE and IPC during the educational program had an impact on prehospital emergency care nurses' (PECN) self-reported competence towards the end of the study program. 


\subsection{Context - The ambulance service}

Ambulance services differ around the world; some countries have a paramedic-based service, others use emergency medical technicians (EMT) and physicians in their organisation [10,11]. There are also countries that staff their ambulances with registered nurses (RNs) [12,13]. Sweden and Finland have similarities in their ambulance services and both countries staff their ambulances with PECNs and EMTs. The main difference between Finland and Sweden is that Finland in addition has physician-manned units on the roads $[12,14]$. The physicians in Finland work in a team, caring for patients together with the PECNs and EMTs [14]. In the Swedish ambulance service the physicians do not work in the ambulances as clinicians on a daily basis; instead, the Swedish physicians act as medical consultants for the companies delivering care in the ambulance service [12]. The difference in how physicians are involved in the daily work in the ambulance service may indicate that Finland has a higher level of IPC in their ambulance service, since it is known that IPC is more likely to occur if there is a shared responsibility for patient care [7]. A consequence of these differences in the ambulance service is that the level of IPC and the possibilities for IPE differ for personnel working in these services.

\subsection{Context - Education}

There is no consensus regarding education and competence for RNs working in the ambulance service in Europe. To become a PECN in Sweden and Finland requires four years of training; in Sweden, the training starts with three years' of education at university to become an RN and then one additional year of specialist training in prehospital emergency care at the university. In Finland the training to become a PECN is integrated into a four-year training program for RNs at the University of Applied Science. In both countries, the study program is based on current national guidelines of education to become a PECN. The desired competence for PECNs after education can be described as knowledge in areas such as generic, professional and technical skills, leadership, communication and collaboration [15].

The curriculum content in both countries is similar and consists mainly of medical science, medical treatment, clinical judgment, nursing practice and contextual knowledge in prehospital care. A difference between the two countries is that the study program to become a PECN in Sweden leads to a professional and a master's degree, and in Finland to a professional and bachelor's degree. Another difference between the study programs in these two countries is the level of IPE in the curriculum; the Finnish PECN students have a formal interprofessional course (7.5 ECTS) with medical students in the curriculum. The interprofessional course is a one-week course distributed over one semester, equivalent to 7.5 credits in accordance with the European Credit Transfer and Accumulation System (ECTS), a standard for comparing the attainment and performance of students of higher education. In Finland, the physicians are also involved in both the theoretical and the practical training during the whole study program. In Sweden, physicians seldom participate in the training and there are no formal interprofessional courses in the study program to become a PECN. These differences in the study program indicate that the Finnish PECN students participate to a greater extent in IPE during their education.

Despite these differences and similarities between Finland and Sweden in the ambulance service and the IPE content in the respective study programs, the PECNs play a crucial role when providing care outside the hospital [16,17]. Therefore, it is important to explore whether the presence of IPE and IPC has an effect on the PECNs' self-reported competence at the point of graduation.

\section{Material and method}

A cross-sectional questionnaire study was conducted among PECN students at one university in Finland and one university in Sweden in 2014.

\subsection{Ethical considerations}

The head of the department at the universities gave us written permission to perform the study. The participants in the study received verbal and written information about the aim of the study. Participation in the study was completely voluntary, filling in the questionnaires was done anonymously and every participant signed an informed consent. All students that received the questionnaire participated in the study. According to Swedish and Finnish regulations, ethical committee approval was not needed. The ethical principles for medical and nursing research involving human subjects were followed $[18,19]$.

\subsection{Data collection and participants}

A questionnaire was distributed to 41 students (19 Finland, 22 Sweden) at two universities during the students' last semester in the study program to become a PECN. The Finnish group consisted of 12 males and seven females aged between 23 and 28 years (median age 25). The Swedish students consisted of 11 males and 11 females aged between 25 and 35 years (median age 28). The questionnaire used for measuring the students' self-reported competence was the Nurse Professional Competence (NPC) Scale. The NPC Scale is a validated tool for measuring self-reported professional competence among both nurse students and RNs working clinically [20,21]. The original NPC Scale [21] was used since all participating students spoke and read Swedish.

\subsection{Questionnaire}

The NPC Scale is constructed on the basis of formal competence requirements determined by the Swedish Board of Health and Welfare [22] and consists of 88 items covering eight competence areas (CA) [23]. CA 1: Nursing care (15 items); CA 2: Value-based nursing care (8 items); CA 3: Medical/technical care (10 items); CA 4: Teaching/learning and support (11 items); CA 5: Documentation and information technology (4 items); CA 6: Legislation in nursing and safety planning (9 items); CA 7: Leadership in and development of nursing care (26 items); CA 8: Education and supervision of staff/ students (5 items) as shown in Appendix 1. A Likert scale was used to measure opinions on perceived competence. Participants rated their agreement with a statement on a four-point Likert scale ranging from "very low degree" $=1$ to "very high degree" $=4$. Students" responses to each of the NPC Scale items were transformed to a score ranging from 1 to 100 . A high score indicated better perceived competence. The response alternative "cannot take a stand-point" was also provided.

\subsection{Statistics}

Statistical analyses were conducted using SPSS, version 20 (SPSS Inc., Chicago, IL, USA). Differences between the groups were tested using a paired $t$-test (two-tailed). The response alternative "cannot take a stand-point" was not used as a value in the statistical calculations. The level of statistical significance (p) was set to 0.05 . 


\section{Results}

A total of 41 students answered the questionnaire, respectively 19 participants from Finland and 22 from Sweden, which was a 100 percent response rate. Overall, according to the NPC Scale, the selfreported professional competence was scored numerically higher in general among the Swedish PECN students. The analyses showed statistically significant differences between the two groups in one competence area 6: Legislation in nursing and safety planning (mean score 2.18 vs. $2.65, \mathrm{p}<0.01$ ). No significant differences were found in any of the other competence areas, as shown in Table 1.

Significant differences between groups at the item level, the students from Finland scored significantly higher on items in competence area 7 (Leadership in and development of nursing) and the students from the Swedish university scored significantly higher on items in competence area 1 (Nursing care), 3 (Medical/technical care) and 6 (Legislation in nursing and safety planning) as shown in Table 2.

\section{Discussion}

The findings show that the Swedish PECN students scored selfreported professional competence numerically higher in general and significantly higher in the competence area "Legislation in nursing and safety planning". This could have been caused by dif- ferences in the academic level among the participating students, in Sweden the education to become a PECN leads to a master's degree and in Finland to a bachelor's degree. A higher academic level among RNs may improve patient outcome [24], and it is reasonable to think that a higher academic level may also affect the students' self-reported professional competence since RNs with a master's degree score themselves as experts to a greater extent compared to nurses with a bachelor's degree [25]. Another perspective on the cause of the higher self-reported professional competence among the Swedish students could be the lack of IPC in the clinical setting. The Swedish students need to develop their professional skills and competence since they have the highest medical knowledge in the clinical setting and therefore they score their professional competence higher. Of course, one could argue that there are opportunities for IPC in the ambulance service [26] even in Sweden since the students collaborate with different professionals such as midwives, firemen, police and EMTs when taking care of patients. However, a positive climate for IPC and to have an RNphysician relationship and shared responsibility for the patient [6-8] are not in place in Sweden at present. An additional explanation for the findings that Swedish students scored self-reported professional competence numerically higher may be that the students in Sweden do not have the possibility to explore other professionals' competencies during their training and they cannot compare their competence with others since the IPC may be considered low in the clinical setting. The students' self-reported

Table 1

Comparison of the factors and scores in the Nurse Professional Competence (NCP) Scales between Finnish students and Swedish students.

\begin{tabular}{|c|c|c|c|}
\hline \multirow[t]{3}{*}{ Competence areas } & Finnish $n=19$ & \multicolumn{2}{|l|}{ Swedish $\mathrm{n}=22$} \\
\hline & \multicolumn{3}{|l|}{ Scores } \\
\hline & Group (mean) & Group (mean) & P-value \\
\hline 1. Nursing care & 78.5 & 82.8 & n.s. \\
\hline 2. Value-based nursing care & 78.8 & 83.3 & n.s. \\
\hline 3. Medical/technical care & 77.5 & 83.5 & n.s. \\
\hline 4. Teaching/learning and support & 70.3 & 68.3 & n.s. \\
\hline 5. Documentation and information technology & 75.8 & 76.0 & n.s. \\
\hline 6. Legislation in nursing and safety planning & 54.5 & 66.3 & $<0.01$ \\
\hline 7. Leadership in and development of nursing & 64.0 & 62.8 & n.s. \\
\hline 8. Education and supervision of staff/students & 68.5 & 68.3 & n.s. \\
\hline
\end{tabular}

Results of the NPC scores are given with values between 1 and 100 (100 indicates a very high degree of self-reported Nurse Professional Competence).

Table 2

Comparison of the items and scores in the Nurse Professional Competence (NCP) Scales between Finnish students and Swedish students.

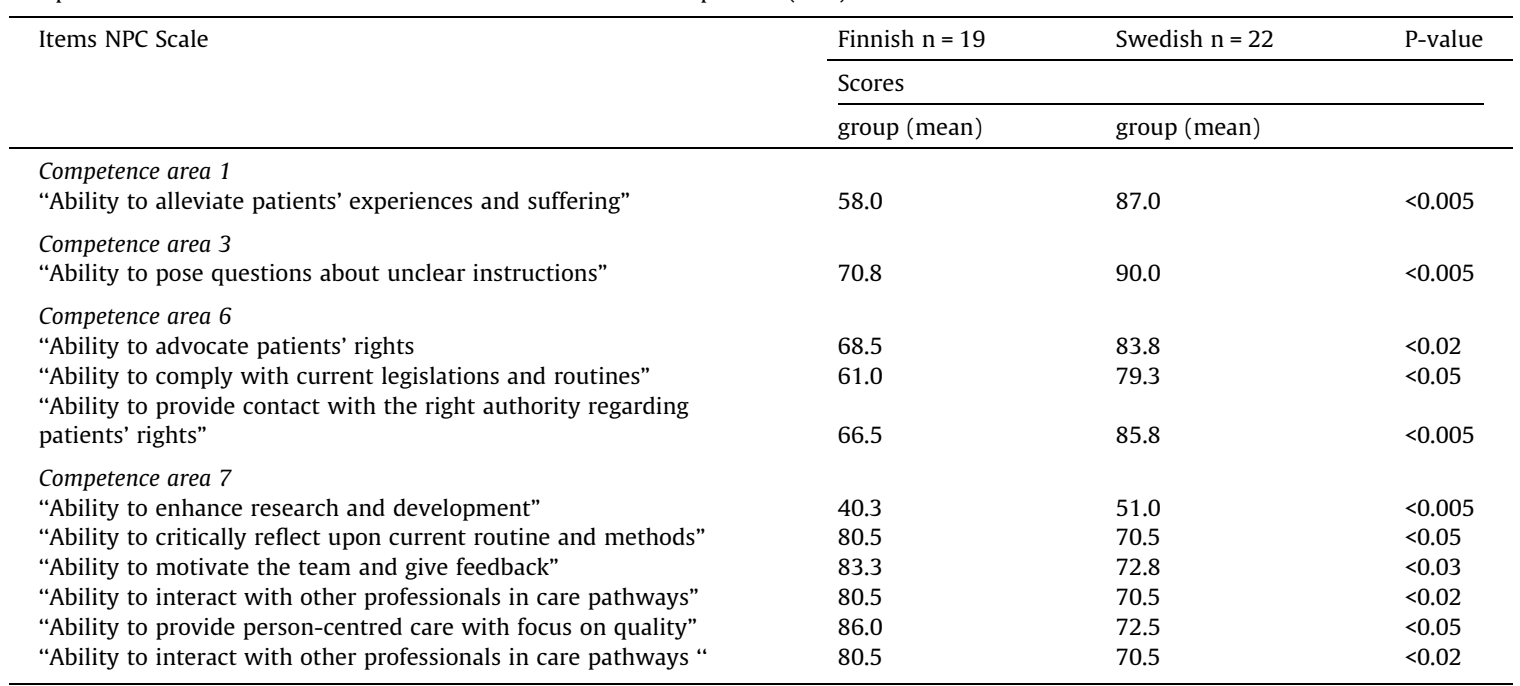

Results of the NPC scores are given with values between 1 and 100 (100 indicates a very high degree of self-reported Nurse Professional Competence). 
professional competence and level of awareness of IPC may also be linked with the different course structures and exposure to clinical situations during their clinical rotation. Nevertheless, this reasoning to some extent entails guessing about what factors may have contributed to differences in scores. Future studies are needed to explore professional competences since the PECN plays a crucial role when providing care outside the hospital [16,17].

The Finnish students scored significantly higher on some of the items in competence area 7 (Leadership in and development of nursing, Table 2). This finding may be a reflection on the higher extent of formal an IPE courses and informal IPC during students' training in Finland. IPE is considered to generate a deeper understanding since it involves students working and reflecting together in the patient care during the education [2-4]. IPE also makes it possible for the students to compare their own profession with others and to explore different professional perspectives in the care of the patients [2-4]. Altogether, the formal IPE course in the study program may be an explanation for the higher selfreported scoring among the Finnish students on the items concerning feedback, motivating teams, interacting with other professionals and person-centred care.

In Finland, at the scene of an acute injury or illness, the ambulance service provides IPC when deciding on the care and treatment of the patient. How the IPC may affect the patient outcome is not evident but it is known that Finnish patients, compared to Swedish patients, have to some extent a better survival rate after an out-of-hospital-cardiac arrest $[27,28]$. However, it is not known if the survival rate is affected by the differences in the IPE and IPC. But as described by Darlow et al. [3], IPE and IPC in the clinical setting may have an effect on patient outcome. Although the Finnish students scored significantly higher on the items of leadership, one could argue that working in collaboration with physicians in the ambulance service could lead to a insecurity in making independent clinical decisions but this is not explored in this study and future research is needed on how the physician presence in the ambulance service may affect the PECNs self-reported professional competence and the patient outcome.

Our hypothesis prior to the study was that at the end of the study program the students would rate themselves higher on the self-reported NPC Scale, but the overall results were lower than expected in general in both countries. We assumed that students need to reach 80 percent of the maximum score (mean $>3.1 / 4.0$ ). The mean score among the Finnish students was 2.7 , and only 50 percent of them had a mean score 3.1 or higher. Forty-seven percent of the Swedish students achieved scores over 3.1, and the mean score was 2.9. Construction of an effective study program is challenging and tools are needed to document improvements and retention of nursing skills and professional competence $[29,30]$. In order to document the improvement of performance, training assessment must provide reliable data [30,31]. Standardized reporting of caring outcomes is needed in order both to compare the quality of care and performance after various training methods [30], and to compare the performance of individuals, and finally to set an absolute value to assess professional competence [31]. Competence assessments are recommended as tools for planning healthcare professionals' education and careers to ensure both a high level of competence and motivation during the education of RNs [32]. It is important that PECNs are given a tailored education in line with the requirements the care organisations place on them. In line with policy approaches on health care and education [1], combining IPC, IPE and a higher academic degree may be the best combination when developing the ambulance service and the education for PECNs.

\subsection{Limitations}

There are some limitations that have to be considered in the study. Overall, factors such as; prior nursing experience, course prerequisites, and differing life experiences may have contributed to different scores in this study. It is known from RNs' descriptions in previous studies that these factors may affect their professional development [33]. In this study the Finnish participants were younger and consisted of more males, and this may have affected our study findings. However, this is not investigated in the study due to the relative small sample size, but further research is needed to explore how these factors may have an effect on selfrated professional competence in the context of the ambulance service. The used NPC Scale has been shown to have the sensitivity to measure differences across groups but it has not been used on PECN students, although it is reasonable to think that the PECN students self-report their professional competence in the same way as other RNs. The NPC Scale has not been validated in Finnish conditions but the ambulance services and the educational systems in both countries are similar and the original Swedish NPC Scale was used without any translation. The results may have been affected by the relatively small sample size, but the results show that the used NPC Scale has the sensitivity to measure differences in relatively small groups, and the students' self-reported professional competence in this study represents their own assessment.

\subsection{Future directions}

When conducting research on the effects of IPE and IPC in the ambulance service there is a need for a larger sample size in order to be able to generalize the findings. A larger sample size is also needed to identify any age or gender differences using NPC Scale. A repetition of the survey and/or interviews with the PECN in the clinical setting could also generate additional research questions. A comparison among other new graduates in different specialist contexts such as intensive care could be of interest to investigate to explore if self-rated competencies are related to entering a new profession as a specialist nurse.

\section{Conclusion}

The findings show that there is a difference between the Swedish and Finnish students' self-reported professional competence as assessed on the point of graduation. The students from Finland scored significantly higher on the items related to interprofessional teamwork, and the Swedish students scored higher on the items related to patients' rights, environmental safety, quality development and research. However, both the Swedish and Finnish students' self-reported professional competence was relatively low according to the NPC Scale, and this indicates that changes need to be made in training programs for PECNs to ensure greater confidence and competence during their education. Increasing IPC and IPE in combination with offering a higher academic degree or the same preparation across Scandinavian countries may be an option when developing the ambulance service and the study program for PECNs.

\section{Conflicts of interest}

The authors have no conflicts of interest to declare. 


\section{Statement}

The manuscript is original and has not previously been published elsewhere, and is not in the process of being considered for publication in another journal.

\section{Funding}

This research did not receive any specific grant from funding agencies in the public, commercial, or not-for-profit sectors.

\section{Appendix 1. The nurse professional competence (NPC) Scale}

Items $(\mathrm{n}=88)$

Ability to ...

Nursing care, 15 items

- Enhance patient health

- Independently apply the nursing process (assessment)

- Independently apply the nursing process (nursing diagnosis)

- Independently apply the nursing process (nursing intervention)

- Independently apply the nursing process (planning, implementation and evaluation) - Meet patient's basic physical needs

- Meet patient's specific physical needs

- Meet patient's psychological and social needs

- Meet patient's cultural and spiritual needs

- Manage changes in patient's physical status

- Document patient's physical status

- Manage changes in patient's psychological status

- Document patient's psychological status

- Recognize patient's experiences and suffering

- Alleviate patient's experiences and suffering

Value-based nursing care, 8 items

- Respectfully communicate with patients, relatives and staff

- Perform nursing care based on humanistic values

- Show respect for patient autonomy, integrity and dignity

- Enhance patients' and relatives' knowledge and experiences

- Show respect for different values and beliefs

- Act upon patients' and relatives' wishes and needs

- Use principles of research ethics

- Contribute to a holistic view of the patient

Medical technical care, 10 items

- Manage drugs and clinical application of knowledge in pharmacology

- Independently perform or participate in examinations and treatments

- Independently administer prescriptions

- Pose questions about unclear instructions

- Support patients during examinations and treatments

- Follow up on patient's conditions after examinations and treatments

- Handle medical/technical equipment according to legislation and safety routines

- Apply hygienic principles and routines

- Prevent complications in relation to care

- Prevent transmission of pathogenic microorganisms

Teaching/learning and support, 11 items

- Provide patients and relatives with support to enhance participation in patient care
- Inform and educate individual patients and relatives

- Inform and educate groups of patients and relatives

- Make sure that information given to the patient is understood

- Pay attention to patients who do not themselves express information needs

- Motivate the patient to adhere to treatments

- Identify and prevent risk factors for ill health

- Motivate changes in lifestyle

- Identify and assess patient's ability to self-care

- Educate and support patients and relatives individually to enhance health

- Educate and support patients and relatives in groups to enhance health

Documentation and information technology, 4 items

- Make use of relevant data in patient records

- Scrutinize the quality of own documentation

- Use information technology as a support in nursing care

Legislation in nursing and safety planning, 9 items

- Comply with current legislation and routines

- Handle sensitive personal data in a safe way

- Advocate patients' rights

- Provide contact with the right authority regarding patients' rights

- Comply with safety routines and notify according to current legislation

- Act adequately in the event of unprofessional conduct among employees

- Manage violent and/or threatening situations

- Act according to regulations in case of a fire or other devastating events

- Apply principles of disaster medicine

Leadership in and development of nursing, 26 items

- Participate in continuous quality assurance and patient safety work

- Act based on an environmentally friendly perspective

- Motivate and contribute to a good care environment

- Care for an esthetical care environment

- Participate in improvement of work environments

- Observe work-related risks and prevent them

- Critically reflect upon current routines and methods

- Inspire dialogue for implementation of new knowledge

- Search and review relevant literature for evidence-based nursing

- Implement new knowledge for evidence-based nursing

- Initiate, participate in and/or carry out development activities for improved care

- Initiate and participate in research

- Independently analyze own professional strength and weaknesses

- Continuously engage in professional development

- Lead and develop health staff teams

- Evaluate actions taken by the health staff teams

- Develop groups and manage conflicts

- Motivate the team and give feedback

- Involve staff in how to develop patient care

- Provide person-centered care with focus on quality

- Provide person-centered care with focus on economy

- Enhance research and development

- Lead and provide nursing care based on best knowledge

- Participate in strategic and evaluation 
- Interact with other professionals in care pathways

- Enhance information and communication to obtain continuity, effectiveness and quality

Education and supervision of staff/students, 5 items

- Participate in supervision of staff/students in development activities for improved care

- Teach, supervise and assess students

- Supervise and educate staff

- Development of health-care teams

- Enable multiprofessional education activities to optimize patient care?

\section{J. Nilsson et al. / Nurse Education Today (2013)}

\section{References}

[1] WHO. Framework for action on interprofessional education and collaborative practice. WHO reference number: WHO/HRH/HPN/10.3. Retrieved 28th July, 2016; 2010.

[2] Baker C, Pulling C, McGraw R, Dagnone JD, Hopkins-Rosseel D, Medves J. Simulation in interprofessional education for patient-centred collaborative care. J Adv Nurs 2008;64(4):372-9. http://dx.doi.org/10.1111/i.1365 2648.2008.04798.x

[3] Darlow B, Coleman K, McKinlay E, Donovan S, Beckingsale L, Gray B, Pullon S. The positive impact of interprofessional education: a controlled trial to evaluate a programme for health professional students. BMC Med Educ 2015;15:98. http://dx.doi.org/10.1186/s12909-015-0385-3.

[4] Morphet J, Hood K, Cant R, Baulch J, Gilbee A, Sandry K. Teaching teamwork: an evaluation of an interprofessional training ward placement for health care students. Adv Med Educ Pract 2014;5:197-204. http://dx.doi.org/10.2147/ amep.s61189.

[5] Reeves S, Perrier L, Goldman J, Freeth D, Zwarenstein M. Interprofessional education: effects on professional practice and healthcare outcomes (update) Cochrane Database Syst Rev 2013;3:Cd002213. http://dx.doi.org/10.1002 14651858.CD002213.pub3.

[6] Crawford CL, Omery A, Seago JA. The challenges of nurse-physician communication: a review of the evidence. J Nurs Adm 2012;42(12):548-50. http://dx.doi.org/10.1097/NNA.0b013e318274b4c0.

[7] San Martin-Rodriguez L, Beaulieu MD, D’Amour D, Ferrada-Videla M. The determinants of successful collaboration: a review of theoretical and empirical studies. J Interprof Care 2005;19(Suppl. 1):132-47. http://dx.doi.org/10.1080 13561820500082677.

[8] Vyt A. Interprofessional and transdisciplinary teamwork in health care Diabetes Metab Res Rev 2008;24(Suppl 1):S106-9. http://dx.doi.org/10.1002/ dmrr.835.

[9] Regan S, Laschinger HK, Wong CA. The influence of empowerment, authentic leadership, and professional practice environments on nurses' perceived interprofessional collaboration. J Nurs Manag 2016;24(1):E54-61. http://dx. doi.org/10.1111/jonm.12288.

[10] Pozner CN, Zane R, Nelson SJ, Levine M. International EMS systems: The United States: past, present, and future. Resuscitation 2004;60(3):239-44. http://dx. doi.org/10.1016/i.resuscitation.2003.11.004.

[11] Sikka N, Margolis G. Understanding diversity among prehospital care delivery systems around the world. Emerg Med Clin North Am 2005;23(1):99-114. http://dx.doi.org/10.1016/i.emc.2004.09.007.

[12] Lindström V, Bohm K, Kurland L. Prehospital care in Sweden, from a transport organisation to advanced health care. Notfall + Rettungsmedizin 2015;18 (2):107-9.

[13] Williams R. Nurses who work in the ambulance service. Emerg Nurse 2012;20 (2):14-7. http://dx.doi.org/10.7748/en2012.05.20.2.14.c9102.

[14] Langhelle A, Lossius HM, Silfvast T, Bjornsson HM, Lippert FK, Ersson A, Soreide E. International EMS systems: the Nordic countries. Resuscitation 2004;61 (1):9-21. http://dx.doi.org/10.1016/j.resuscitation.2003.12.008.
[15] Wihlborg J, Edgren G, Johansson A, Sivberg B. The desired competence of the Swedish ambulance nurse according to the professionals - a Delphi study. Int Emerg Nurs 2014;22(3):127-33. http://dx.doi.org/10.1016/i.ienj.2013.10.004.

[16] Selker HP, Beshansky JR, Ruthazer R, Sheehan PR, Sayah AJ, Atkins JM, Griffith $\mathrm{JL}$. Emergency medical service predictive instrument-aided diagnosis and treatment of acute coronary syndromes and ST-segment elevation myocardial infarction in the IMMEDIATE trial. Prehosp Emerg Care 2011;15(2):139-48. http://dx.doi.org/10.3109/10903127.2010.545478.

[17] Wallgren UM, Castren M, Svensson AE, Kurland L. Identification of adult septic patients in the prehospital setting: a comparison of two screening tools and clinical judgment. Eur J Emerg Med 2014;21(4):260-5. http://dx.doi.org/ 10.1097/mej.0000000000000084.

[18] ICN. (2012). (International Council of Nurses) The ICN code of ethics for nurses Retrieved 1 august, 2014, from http://www.icn.ch/images/stories/documents/ about/icncode_english.pdf.

[19] WMA. WMA International Code of Medical Ethics. 4th Retrieved 24 august, 2015, from http://www.wma.net/en/30publications/10policies/c8/; 2006.

[20] Leksell J, Gardulf A, Nilsson J, Lepp M. Self-reported conflict management competence among nursing students on the point of graduation and registered nurses with professional experience. J. Nurs. Educ. Pract. 2015;5:82-9.

[21] Nilsson J, Johansson E, Egmar A-C, Florin J, Leksell J, Lindholm C, Gardulf A. Nursing education in a globalized world: Nursing students with international study experience report higher competence at graduation. Open J Nurs 2014;4:848-58.

[22] Socialstyrelsen. Competence Description for Registered Nurse (In Swedish: Kompetensbeskrivning För Legitimerad Sjuksköterska) (2005-105-1). Stockholm, Sweden: National Board of Health and Welfare. In Swedish: Socialstyrelsen; 2005. Retrieved from <http://www.socialstyrelsen. se/Lists/Artikelkatalog/Attachments/9879/2005-105-1_20051052.pdf>.

[23] Nilsson J, Johansson E, Egmar AC, Florin J, Leksell J, Lepp M, Gardulf A. Development and validation of a new tool measuring nurses self-reported professional competence-the nurse professional competence (NPC) scale. Nurse Educ Today 2014;34(4):574-80. http://dx.doi.org/10.1016/j. nedt.2013.07.016.

[24] Aiken LH, Sloane DM, Bruyneel L, Van den Heede K, Griffiths P, Busse R, Sermeus W. Nurse staffing and education and hospital mortality in nine European countries: a retrospective observational study. Lancet 2014;383 (9931):1824-30. http://dx.doi.org/10.1016/s0140-6736(13)62631-8.

[25] McHugh MD, Lake ET. Understanding clinical expertise: nurse education, experience, and the hospital context. Res Nurs Health 2010;33(4):276-87. http://dx.doi.org/10.1002/nur.20388.

[26] McLelland G, McKenna L, Morgans A, Smith K. Paramedics involvement in planned home birth: a one-year case study. Midwifery 2016;38:71-7. http:// dx.doi.org/10.1016/j.midw.2016.02.007.

[27] Hiltunen P, Kuisma M, Silfvast T, Rutanen J, Vaahersalo J, Kurola J. Regional variation and outcome of out-of-hospital cardiac arrest (ohca) in Finland - the Finnresusci study. Scand J Trauma Resusc Emerg Med 2012;20:80. http://dx. doi.org/10.1186/1757-7241-20-80.

[28] Stromsoe A, Svensson L, Claesson A, Lindkvist J, Lundstrom A, Herlitz J. Association between population density and reported incidence, characteristics and outcome after out-of-hospital cardiac arrest in Sweden. Resuscitation 2011;82(10):1307-13. http://dx.doi.org/10.1016/j. resuscitation.2011.04.025.

[29] van Leeuwen R, Tiesinga LJ, Middel B, Post D, Jochemsen H. The validity and reliability of an instrument to assess nursing competencies in spiritual care. J Clin Nurs 2009;18(20):2857-69. http://dx.doi.org/10.1111/i.13652702.2008.02594.x

[30] Wass V, Van der Vleuten C, Shatzer J, Jones R. Assessment of clinical competence. Lancet 2001;357(9260):945-9. http://dx.doi.org/10.1016/s01406736(00)04221-5.

[31] Brennan RT, Braslow A, Batcheller AM, Kaye W. A reliable and valid method for evaluating cardiopulmonary resuscitation training outcomes. Resuscitation 1996;32(2):85-93.

[32] Numminen O, Meretoja R, Isoaho H, Leino-Kilpi H. Professional competence of practising nurses. J Clin Nurs 2013;22(9-10):1411-23. http://dx.doi.org/ 10.1111/j.1365-2702.2012.04334.x.

[33] Khomeiran RT, Yekta ZP, Kiger AM, Ahmadi F. Professional competence: factors described by nurses as influencing their development. Int Nurs Rev 2006;53 (1):66-72. http://dx.doi.org/10.1111/j.1466-7657.2006.00432.x. 